\title{
Paediatric Virology and its interaction between basic science and clinical practice (Review)
}

\author{
IOANNIS N. MAMMAS ${ }^{1}$, ANNE GREENOUGH ${ }^{2}$, MARIA THEODORIDOU ${ }^{3}$, ANNA KRAMVIS ${ }^{4}$, \\ MARIA RUSAN ${ }^{5}$, ANGELIKI MELIDOU $^{6}$, PARASKEVI KOROVESSI $^{7}$, GEORGIA PAPAIOANNOU $^{8}$, \\ ALEXIA PAPATHEODOROPOULOU ${ }^{9}$, CHRYSSIE KOUTSAFTIKI $^{10}{ }^{10}$, MARIA LISTON ${ }^{11}$, \\ GEORGE SOURVINOS $^{1}$ and DEMETRIOS A. SPANDIDOS ${ }^{1}$
}

\author{
${ }^{1}$ Department of Clinical Virology, School of Medicine, University of Crete, Heraklion 71003, Greece; \\ ${ }^{2}$ Division of Asthma, Allergy and Lung Biology, King's College London, London SE5 9RS, UK; ${ }^{3} 1$ st Department of Paediatrics, \\ 'Aghia Sophia' Children's Hospital, University of Athens School of Medicine, Athens 11527, Greece; \\ ${ }^{4}$ Hepatitis Virus Diversity Research Unit, School of Clinical Medicine, Faculty of Health Sciences, \\ University of the Witwatersrand, Johannesburg 2193, South Africa; ${ }^{5}$ Department of Medical Oncology, \\ Dana-Farber Cancer Institute, Boston, MA 02115, USA; ${ }^{6}$ 2nd Laboratory of Microbiology, School of Medicine, \\ Aristotle University of Thessaloniki, Thessaloniki 54124; ${ }^{7}$ Department of Paediatrics, 'Penteli' Children's Hospital, \\ Penteli 1523; ${ }^{8}$ Department of Paediatric Radiology, 'Mitera' Children's Hospital, Athens 15123; \\ ${ }^{9}$ Paediatric Intensive Care Unit (PICU), 'Aglaia Kyriakou' Children's Hospital, Athens 11527; \\ ${ }^{10}$ Paediatric Intensive Care Unit (PICU), 'Penteli' Children's Hospital, Penteli 15236, Greece; \\ ${ }^{11}$ Department of Anthropology, University of Waterloo, Waterloo, ON N2L 3G1, Canada
}

Received October 19, 2017; Accepted December 28, 2017

DOI: $10.3892 /$ ijmm.2018.3364

\begin{abstract}
The 3rd Workshop on Paediatric Virology, which took place on October 7th, 2017 in Athens, Greece, highlighted the role of breast feeding in the prevention of viral infections during the first years of life. Moreover, it focused on the longterm outcomes of respiratory syncytial virus and rhinovirus infections in prematurely born infants and emphasised the necessity for the development of relevant preventative strategies. Other topics that were covered included the vaccination policy in relation to the migration crisis, mother-to-child transmission of hepatitis $\mathrm{B}$ and $\mathrm{C}$ viruses, vaccination against human papilloma viruses in boys and advances on intranasal live-attenuated vaccination against influenza. Emphasis was also given to the role of probiotics in the management of viral infections in childhood, the potential association between viral infections and the pathogenesis of asthma, fetal and neonatal
\end{abstract}

Correspondence to: Professor Demetrios A. Spandidos, Department of Clinical Virology, School of Medicine, University of Crete, Heraklion 71003, Greece

E-mail: spandidos@spandidos.gr

Key words: Paediatric Virology, viral infections, breast feeding, respiratory syncytial virus, premature neonates, migration crisis, hepatits $\mathrm{B}$, hepatitis $\mathrm{C}$, human papillomavirus, probiotics, brain imaging, Paediatric Intensive Care Unit, asthma, influenza, Athenian Agora, continuing medical education brain imaging and the paediatric intensive care of children with central nervous system viral infections. Moreover, an interesting overview of the viral causes of perinatal mortality in ancient Greece was given, where recent archaeological findings from the Athenian Agora's bone well were presented. Finally, different continuing medical educational options in Paediatric Virology were analysed and evaluated. The present review provides an update of the key topics discussed during the workshop.

\section{Contents}

1. Introduction

2. Plenary key topics

3. Update on current views and advances on Paediatric Virology

\section{Introduction}

Viral neonatal and paediatric infections are characterised by a great heterogeneity of clinical manifestations and are considered as major causes of neonatal and paediatric morbidity and mortality (1). Almost 50 years ago, Paediatric Virology was not considered an isolated discipline and was included in the Paediatric Infectious Diseases section of the scientific field of Paediatrics (2,3). However, during the past two decades, new advances in the field of Clinical Virology and Molecular Medicine have expanded the level of knowledge on the prevention, diagnosis and treatment of viral infections 
occurring in infancy and childhood $(4,5)$. These developments and changes highlight the demand for undergraduate and postgraduate medical education in Paediatric Virology, which combines Paediatrics with Virology, Epidemiology, Molecular Medicine, Evidence-based Medicine, Clinical Governance, Quality Improvement, and Pharmacology and Immunology (5).

The 3rd Workshop on Paediatric Virology was entitled 'Paediatric Virology: Interaction between basic science and clinical practice'. It was held on October 7th, 2017 in Athens, Greece, as an official session of the 22nd World Congress on Advances in Oncology and the 20th International Symposium on Molecular Medicine. Its aim was to bring together virologists and paediatric health professionals and encourage them to collaborate as an international network to promote paediatric health. Moreover, during the workshop, Nobelist laureate Professor Harald zur Hausen, Emeritus Professor of Virology at the University of Freiburg in Germany, who received the 2008 Nobel Prize in Physiology or Medicine for his discovery of human papilloma viruses (HPVs) causing cervical cancer and Professor Anne Greenough, Professor of Neonatology and Clinical Respiratory Physiology at King's College London, UK and Vice President of Science and Research at the Royal College of Paediatrics and Child Health (RCPCH), were honoured by the Paediatric Virology Study Group (PVSG) for their indisputable academic, research and publishing contribution to Paediatric Virology.

The present review provides an overview on the wealth of new material from different areas of neonatal and paediatric viral infections presented and discussed during the workshop. Interestingly, 7 out of the 10 top key messages (Table I) of our meeting, as well as both statements of Nobelist laureate Professor Harald zur Hausen, on the occasion of this workshop (Table II), included recommendations on specific prevention strategies against viral infections. Along with the significant role of human breast milk and respiratory syncytial virus (RSV) prophylaxis, these issues included the necessity of the vaccination policy in relation to the migration crisis, prevention of hepatitis in newborns, recent advances on influenza vaccines, male vaccination against HPVs and the the preventative role of probiotics in the management of viral infections in children.

\section{Plenary key topics}

The importance of diet during the first years of life. A number of different infections occur during the early period of life (6). Several of these infections are viral, e.g., herpes-group viruses, polyomaviruses and Torque teno viruses, and these result in long-time persistence and latency within human specific cell types (6). The fate of the latent genomes seems to vary substantially. They may remain dormant for the whole lifetime without any recognisable side effect. During prolonged latency, their genomes may become defective and can eventually be degraded. In particular, herpes-group viruses may become re-activated, leading locally to viral production and cell lysis. The interaction of the latent genomes with mutagenic chemical, physical or other biological factors may dysregulate the control of latency or persistence and may thus result in local exacerbations, mainly as the result of immunoreactivity (6).

Prolonged human breast feeding ( $>6$ months) has been documented to have a beneficial effect on the avoidance of viral infections, e.g., norovirus- and rotavirus-related infections, which can potentially be lethal for newborn babies (7). It has also been shown that it reduces the risk of developing certain malignant tumours arising in early childhood, e.g., acute lymphoblastic leukemia (ALL), or in young adolescence, e.g., Hodgkin's disease (HD). Apparently, specific sugars in human milk modify the receptors blocking the uptake of noroviruses and rotaviruses during the breast feeding phase. The maturation of the immune system during this period, subsequently, facilitates an effective immune response during the weaning period. The uptake of specific sialic acids, not produced in humans, but present in cow milk and meat products, beginning during the weaning time, results in their incorporation into the cell surface glycoproteins and gangliosides. The resulting modification of cell surface receptors alters their susceptibility to specific viral infections, e.g., human polyomavirus type 9 and others. Current analyses suggest that these receptors now permit the binding of infectious agents present in dairy cattle serum and milk products, leading to their longtime persistence and latency and their potential pathogenicity under conditions of reactivation. Thus, the protective effects of breast feeding, which allows for the maturation of the immune response during the first years of life, emerges as critical period, which determines the uptake and latency of specific infections (7).

Long term effects of viral infections on prematurely born infants. Chronic respiratory morbidity is common in prematurely born infants and has a multifactorial aetiology (8). Lower respiratory tract infections (LRTIs) caused by RSV increase this morbidity. Although prematurely born infants are functionally $(9,10)$ and genetically $(11)$ predisposed to RSV LRTIs, their lung function in infancy is worse after the LRTI $(12,13)$. RSV LRTIs have more long-term effects, as evidenced by very prematurely born infants, who have bronchopulmonary dysplasia (BPD) and then subsequently suffer from an RSV LRTI hospitalisation; in the first 2 years after birth these infants need increased healthcare utilisation and have poorer pulmonary functions at school age (14). There are limited data to suggest that rhinovirus (RV) may adversely affect on respiratory-related outcomes in prematurely born infants. In a previous study, in 8 prematurely born infants with BPD, the development of RV LRTIs was associated with a sustained worsening of their clinical status, requiring the addition of novel therapies for prolonged periods of time (15). Furthermore, in another study, prematurely born infants, who had developed RV LRTI, during infancy, had higher healthcare utilisation costs, including greater numbers of hospital, outpatient and respiratory-related general practitioner (GP) attendances, than infants without a viral LRTI (16).

Ongoing research at King's College London (UK) has recently re-examined prematurely born cohorts at school age (5-8 years) for whom data on all respiratory viral infections in infancy, as well as whether or not hospital admission was required were recorded (17). The RV group had a poorer lung function than those who had not suffered an LRTI during infancy. Cluster analysis of the data demonstrated that infants with an extremely low birthweight requiring prolonged ventilation were at an increased risk of suffering from an RV LRTI in infancy and had higher healthcare utilisation and impaired lung function at school age (18). These data suggest that both 
Table I. The 10 top key messages of the ‘3rd Workshop on Paediatric Virology’.
Breast feeding
'Breast feeding has beneficial effects on the prevention of infections during the first years of life and should be promoted by primary paediatric health care providers.'
RSV prophylaxis 'The increased chronic respiratory morbidity in prematurely born infants due to RSV should be taken into consideration when developing of relevant preventative strategies.'

HPV vaccination 'HPV vaccine uptake should be promoted in countries with low HPV vaccination rates to reduce the cervical and anogenital cancer burden, as well as for the prevention of genital warts. Inclusion of males in childhood HPV immunisation programmes should be considered.'

Migration crisis 'Children's vaccination should be a priority during the current migration problem; we strongly support childhood vaccination for all children in Europe.'

HBV vaccination 'Prevention of mother-to-child transmission of HBV is possible: the vaccine against HBV should be administered at birth within $24 \mathrm{~h}$ regardless of maternal HBV status.'

Influenza 'Recent pilot studies in Europe have shown that LAIV can directly prevent childhood infections and vaccination indirectly protect the elderly population; continuous enhanced surveillance of circulating influenza viruses and further study results on LAIV effectiveness over consecutive influenza seasons are needed in order to develop optimal vaccination policies.'

Imaging 'Imaging of fetal and neonatal viral infections is unable to provide the specific diagnosis; however it can contribute in defining the extent of involvement and reveal the consequences that affect the outcome.'

Probiotics 'To date, several studies have intimated a role of probiotics in modifying the frequency and severity of respiratory and gastrointestinal viral infections in infants and children; however, further studies are required in order to understand their potential therapeutic and preventative role.'

Archaeology 'Collaboration between archaeologists and experienced paediatric infectious diseases specialists is necessary for the better understanding and interpretation of various recent archaeological findings related to viral-induced neonatal mortality.'

Medical education 'Medical education in Paediatric Virology among practicing paediatricians should be promoted; we strongly support the creation of an educational e-platform on Paediatric Virology.'

RSV, respiratory syncytial virus; HPV, human papilloma virus; HBV, hepatitis B virus; LAIV, live attenuated influenza vaccines.

RSV and RV LRTI increase chronic respiratory morbidity in prematurely born infants and, as a consequence, this should be taken into consideration regarding the development of relevant preventative strategies.

\section{Update on current views and advances on Paediatric Virology}

Migration crisis and vaccination policy. Over the past 2 years, Greece, one of the principal gateway countries of the European Union (EU), has experienced an increased inflow of refugees and migrants arriving by sea to the Greek islands, such as the Dodecanese Islands, Lesbos, Samos and Agathonisi (19-21). By the end of 2015, 856,723 individuals in total had arrived in the country, while between January 1st and November 13th, 2016, the corresponding number reported by the International Organization for Migration (IOM) was 170,553 individuals $(21,22)$. The majority of individuals arriving in Greece came from Syria (approximately 60\%), followed by Afghanistan, Iraq, Pakistan and Algeria (23). Following the implementation of the EU-Turkey agreement and the closure of the Northern borders of Greece in March 2016,>60,000 refugees and migrants remain stranded in the country, out of which $37 \%$ are children (19).

It is worth noting that, to date, several studies have highlighted lower immunisation coverage among refugees and migrants compared to European-born individuals (24). This has been attributed to the low vaccination coverage in their countries of origin due to the collapse or inadequacy of their healthcare systems. Several problems have also limited the access of refugees and migrants to vaccination in Europe, such as the lack of information regarding their immunisation status, financial problems of the hosting countries and the lack of collaboration among public health authorities of European countries. According to the World Health Organization (WHO), a high vaccination coverage is required for the protection of refugees, migrants and asylum seekers, as well as for the population of the hosting countries, which should ensure appropriate vaccinations, extending their routine immunisation schedule to individuals on the move irrespective of their legal status (25).

In Greece, an imperative need emerged for implementing supplementary immunisation activities, particularly to refugee children living in the 'Points of care', all over the country (19). Vaccinations were conducted in the form of a mass campaign by non-governmental organisations (NGOs) that have significant experience and expertise in conducting such campaigns, such as Médecins Sans Frontières (MSF), the Red Cross and Doctors of the World, under the coordination of the General Secretariat for Public Health of the Hellenic Ministry of Health. In this framework, the recommendations on refugees and migrants vaccination of the National Immunisation Committee were followed and $>30,000$ vaccines were given (26). According to 
Table II. Statements of Nobelist laureate Professor Harald zur Hausen, Emeritus Professor of Virology at the University of Freiburg, on the occasion of the '3rd Workshop on Paediatric Virology'.

Breast feeding 'Prolonged breast feeding is clearly of great benefit for babies. Human milk contains some species-specific sugars, which block the uptake of potentially dangerous viruses (e.g., noro- and rotaviruses), which are the cause for high infant mortality for newborn children, specifically in developing parts of this world. During a period of $\sim 6$ months of breast feeding the immune system matures and subsequently such infections have a less deleterious impact. The uptake, however, of 5-N-glycolyl-neuraminic acid (not produced in humans) by bovine milk and meat leads to the incorporation of this sialic acid into cellular glycoproteins and modifies those receptors, rendering them susceptible for other virus infections (e.g., human polyomavirus type 9 and others).'

HPV 'Vaccination of boys against HPV should be included in the national vaccination programmes at the same age vaccination as girls (8-14 years). Males are the main transmitters of high risk HPV, having more HPV-positive oropharyngeal and anal cancers than females, and in particular homosexual males would not profit from a herd effect, when $80 \%$ or even more of females had been vaccinated. Since, in addition, in most countries the vaccination rate ranges between $20-40 \%$ or less, vaccination of boys should be mandatory.'

HPV, human papilloma virus.

data collected by the Ministry of Health Working Group for the coordination of refugees/migrants vaccination from May 2016 to 20 January, 2017, the children were vaccinated for 10 infectious vaccine-preventable diseases, out of which 5 were viral infections (26). The estimated coverage (with 1st swoop) among children of appropriate age for each vaccine was: Measles, mumps and rubella (MMR), 83\%; diphtheria, tetanus, pertussis and poliomyelitis, pertussis, $82 \%$; pneumococcal disease, $76 \%$; haemophilus influenzae type B, 75\%; and hepatitis B, 79\%.

Taking into account the difficulties, including vaccine supply, the above-mentioned results are really encouraging (19). In fact, it is important that a great number of immunised refugee children are regularly attending lessons in Greek schools. Public Health Authorities and NGOs have indeed worked hard together, in order to protect children, living through one of the biggest crisis of our times, from infectious diseases. The challenge, today, is to continue the immunisation of refugees and migrants in Greece, as part of routine primary healthcare and to develop a plan for providing immunisation to all newly-arrived refugees and migrants. For this reason, an effective strategy should be to tailor immunisation services on the specific needs of the target populations (27).

Mother-to-child transmission of hepatitis viruses. Chronic infections with hepatitis B virus (HBV) and hepatitis C virus $(\mathrm{HCV})$ are responsible for $90 \%$ of all hepatitis mortalities globally, with an estimated 257 million individuals infected with HBV and another 71 million with HCV (28). As $90 \%$ of infants infected with $\mathrm{HBV}$ at birth will become chronic carriers, motherto-child transmission (MTCT) is responsible for $35-50 \%$ of the chronic HBV infections (29), which can develop into severe liver disease including hepatocellular carcinoma (HCC) and cirrhosis. Compared to horizontal transmission, MTCT can increase the risk of the development of HCC (30). MTCT of HBV occurs mostly during birth and more rarely in utero or post-natally. The risk is increased in $\mathrm{HBeAg-positive} \mathrm{mothers} \mathrm{compared}$ to $\mathrm{HBeAg-negative} \mathrm{mothers.} \mathrm{There} \mathrm{are} \mathrm{also} \mathrm{geographical}$ differences in the risk of MTCT of HBV, being higher in Asia than in Africa (31). MTCT of HCV occurs at a rate of 5\% and is the major cause of paediatric $\mathrm{HCV}$ infection (32).
The prevention of MTCT of HBV and HCV is one of the 5 synergistic measures adopted by the 194 member states of the WHO in their commitment towards the elimination of viral hepatitis as a public health threat by 2030 (33). The prevention of MTCT of HBV can be achieved in $99 \%$ of cases, by delivering the birth dose of the HBV vaccine within $24 \mathrm{~h}$ of birth. The risk of MTCT of HBV is highest in infants born to younger mothers, who are HBeAg-positive and with high viral loads. Vaccination with $<3$ doses is also a risk factor for MTCT of HBV. Testing pregnant women for HBsAg, treating those positive before delivery and administering the birth dose and hepatitis B immunoglobulin (HBIg) to infants at birth can successfully prevent MTCT of HBV (34). The rate of MTCT of HBV can be reduced by caesarian section delivery (35), with breast feeding not posing a risk factor for MTCT of HBV (36). By contrast, neither the mode of delivery nor the type of feeding has been shown to be a risk factor for MTCT in the case of HCV (37). HIV co-infection doubles the risk of MTCT of HCV (38).

Although a high HCV viral load is a risk factor for MTCT (39), it is currently not a preventable risk factor as direct acting antivirals (DAAs) have not been approved during pregnancy. The universal screening for HCV has been shown to be more effective than risk factor-based screening in preventing MTCT. The approval of DAAs in pregnant women and children will open new horizons in the prevention of MTCT of HCV. Interrupting MTCT of HBV and $\mathrm{HCV}$ is an intervention that can contribute to the elimination of viral hepatitis as a public health threat by 2030 and to averting the high morbidity and mortality of the severe liver disease associated with these viral infections.

HPV infections: Aspects of paediatric relevance. HPVs are small, non-enveloped, double-stranded, circular DNA viruses, belonging to the family Papillomaviridae (40-42). HPVs infect epithelial tissue and their life cycle is closely intertwined with the differentiation of the epithelium $(41,42)$. HPV requires the host DNA replication machinery in order to replicate its genome. This maintains the keratinocytes in a proliferative state via the action of specific HPV proteins, of which the best characterised are E6 and E7 and thus, creates an environment amenable to carcinogenesis (43). 
HPVs are known to be the aetiologic agents in cervical cancer and in a significant proportion of anogenital cancers (90\% of anal cancers, 60-90\% of vaginal and vulvar cancers and $30-40 \%$ of penile cancers) (44). More recently, it has become apparent that HPVs are also drivers in a subset of head and neck squamous cell carcinoma cases, in particular tonsillar and base of tongue carcinomas (45). In addition, HPVs are associated with a number of benign neoplasms, including common cutaneous warts, genital warts, oral papillomas and recurrent respiratory papillomatosis (RRP) (44). More than 150 types of HPVs have been discovered to date. These are primarily classified into either low- or high-risk according to their malignant potential, and into mucosal and cutaneous types. HPV-16 is the foremost high-risk type isolated from cervical, anogenital, and head and neck carcinomas.

Paediatric manifestations of HPV infections include skin warts, oral papillomas, RRP and anogenital warts $(46,47)$. Additionally, asymptomatic infections of the oral or tonsillar mucosa, as well as of the genital mucosa in children have been described $(46,47)$. Studies on HPV seropositivity in young children indicate a relatively low prevalence of HPV antibodies (approximately 0-10\%) (48). The seroprevalence significantly increases in adolescence with the commencement of sexual activity. Mucosal HPV infection is often described as a sexually transmitted infection; however, the presence of such infections in infants and young children suggests that the virus may also be vertically and horizontally transmitted. There is strong evidence that maternal HPV cervical infection at the time of delivery can be transmitted to the newborn and there is a strong association between development of juvenile RRP and the presence of maternal genital warts during pregnancy (49). The detection of HPV DNA in spermatozoa and seminal plasma, as well as in amniotic fluid and placental tissue, suggests that peri-conceptual and prenatal transmission may also be possible $(46,47)$. HPV can be transmitted horizontally (i.e., by kissing or touch) or to different sites by auto-inoculation $(46,47)$. In the case of anogenital warts in particular, sexual abuse remains an important consideration. There are a lack of data on the persistence of HPV infections in children and their relation to the subsequent development of HPV-associated diseases, such as oropharyngeal carcinoma.

The routine vaccination of girls, aged 11-12 years, has been introduced in many countries to reduce the incidence of anogenital cancers. The Nobelist laureate Professor Harald zur Hausen has actively advocated the vaccination of boys for the eradication of HPV infection and has emphasised that male HPV vaccination should be included into the current vaccination programmes. His publication with Professor Karin Michels from Harvard Medical School entitled 'HPV vaccine for all' and published in 2009 in Lancet has been one of the very first publications advocating the vaccination of boys (50). To date, the United States, Canada, Australia, and Austria have currently implemented routine vaccination of girls as well as boys (51-53). The recent WHO guidelines recommended the vaccination of girls aged 9-14 years as the primary target population, and the vaccination of additional target populations (females 15 years and older, and males) only if feasible, affordable and cost-effective (54). Gender-neutral vaccination may achieve greater herd protection effects and direct protection of males; however gender-neutral programmes have only been implemented recently and their impact on HPV-related diseases at a population level remains to be determined (54). Nevertheless, there are strong data that quadrivalent HPV vaccination is effective in reducing anal intraepithelial neoplasia (50\% reduction in the intention-to-treat population and $78 \%$ in the per-protocol population) (55). Similar prospective data for penile cancers and oropharyngeal cancers is lacking; however, there are data suggesting that HPV infections at these sites are reduced following vaccination $(56,57)$.

Non-vaccinated children will continue to be affected by paediatric HPV-associated diseases and vaccinated children by HPV types not covered by vaccination. Increasing vaccine coverage may reduce HPV prevalence not only for anogenital infections, but also oral infections. However, vaccination programmes continue to face challenges, in part due to parental fears regarding vaccine safety (58). Large population-based studies have confirmed vaccine safety (59). Educational efforts regarding the importance of HPV vaccination and the vaccine's efficacy and safety profile are necessary to achieve higher vaccination coverage.

Intranasal live-attenuated influenza vaccination in children. Live-attenuated influenza vaccines (LAIV) have been used in certain European countries, such as UK and Finland, and in the USA and Canada for decades $(60,61)$. In addition to their efficient mode of introduction as a nasal spray, in randomised clinical trials, they have been shown to provide better protective efficacy than inactivated influenza vaccines (IIV) in children, which are considered to be the main drivers of influenza transmission. However, recent observational studies have shown conflicting evidence regarding the effectiveness of LAIV. During the 2015/16 influenza season, a reduced vaccine effectiveness (VE) was observed in the United States, and for this reason the Centers for Disease Prevention and Control (CDC) recommended the use of the IIV and the recombinant influenza vaccine (RIV), instead of the LAIV for the 2016/17 season (62). However, in 2015/16, in the UK, Finland and Canada, LAIV VE was shown to be protective against the drifted influenza $\mathrm{A}(\mathrm{H} 3 \mathrm{~N} 2)$ and $\mathrm{B}$ viruses and with suboptimal effectiveness only against $\mathrm{A}(\mathrm{H} 1 \mathrm{~N} 1) \mathrm{pdm} 09$ compared to IIV (63-65). Studies have attributed the reduced effectiveness against $\mathrm{A}(\mathrm{H} 1 \mathrm{~N} 1) \mathrm{pdm} 09$ to the thermal instability of this virus component and the handling conditions of the vaccines (66).

There are certain performance limitations, one of which is that previous influenza vaccination may modify the immune response after a repeated vaccination (60). Further studies are warranted to determine the reasons for reduced VE. A recent systematic literature review did not find any evidence of the decreased efficacy of LAIV when administered during two consecutive seasons (67). On the other hand, the findings of a study that evaluated the impact of repeated vaccination among health care workers were suggestive of decreased serological response among the highly vaccinated group (68). Another consortium, Seasonal Influenza Vaccination Effectiveness II (SIVE II), is currently evaluating the safety and effectiveness of the LAIV programme in children (69). The vaccination of healthy children has the potential to provide both direct protection to children, but also indirect protection to vulnerable groups in the general population. Further studies with large sample sizes and a greater number of people in the vaccine-naïve group and in groups with repeated vaccinations are required. 
Population-based national health registries are also valuable to generate routine data for measuring the vaccination impact in a timely manner. As the LAIV use has been shown to be beneficial over the past years, continuous enhanced surveillance and further study results are required in order to better understand the USA findings and the possible implications for vaccination policies in Europe and worldwide.

Probiotics and viral infections in childhood. Probiotics (e.g., Lactobacilli, Bifidobacteria and Saccharomyces) are live microorganisms, which can confer beneficial health effects on the host, when consumed in adequate amounts (70,71). They are non-pathogenic in the normal host, resist processing and are able to survive in the human digestive tract. Prebiotics (e.g., Fructo- and Galacto-oligosaccharides) are non-viable food components, which can confer a significant health benefit on the host by modulating intestinal microflora. Synbiotics are a combination of pro- and prebiotics. The gut microflora is a complex ecosystem supporting the structure and function of the intestinal mucosa. Probiotics have the ability to modify the gut microflora either by lowering colonic $\mathrm{pH}$ through production of short-chain fatty acids (SCFAs), or by producing antimicrobial compounds and antitoxins, and or by competing with other bacteria for nutrients. They also enhance gut barrier function and play a role in immunomodulation $(72,73)$.

Probiotics have been used for the management of children with acute viral diarrhoea as an adjunct to rehydration therapy (74-76). To date, 5 paediatric meta-analyses have shown that probiotics reduce the duration of diarrhoea, ranging between $-16.8 \mathrm{~h}$ and $-30.0 \mathrm{~h}$, as well as the risk of diarrhoea lasting for $>4$ days (74). The subgroup with rotavirus-associated diarrhoea seemed to be more responsive to probiotics, while Lactobacillus rhamnosus GG (LGG) appeared to be the most effective probiotic (75). The beneficial effects of probiotics seem to be more evident when treatment is initiated early $(<48 \mathrm{~h})$ and are strain- and dose-dependent. Probiotics are not useful for treating bacterial diarrhoea (76).

Probiotics have also been proposed to be helpful in preventing upper respiratory tract infections (URTIs); however the interventions and existing evidence are inconsistent $(77,78)$. A recent systematic review (77) of 14 randomised controlled trials (RCTs) suggested that probiotic prophylaxis reduced the number of children, who had one or more URTIs [odds ratio (OR) $0.58,95 \%$ confidence interval (CI) 0.36 to 0.92 ] and the number of URTIs per person-year (rate ratio $0.88,95 \% \mathrm{CI}$ 0.81 to 0.96 ). Both outcomes had inconsistent results in the individual studies, reflected in estimates of heterogeneity. A better understanding of the effects of different probiotic strains and a deeper insight into their mechanisms of action are required for the validation of specific strains carrying a potential to modify the frequency and severity of URTIs and gastrointestinal viral infections in infants and children (78-80).

Fetal and neonatal brain imaging in viral infections. Fetuses and neonates are susceptible to a wide variety of viral infections most commonly involving the central nervous system (CNS) in greater frequency than adults (81). Infections of the CNS are a very common worldwide health problem in childhood with significant morbidity and mortality. In children, viruses are the most common cause of CNS infections, followed by bacteria, and less frequently by fungi and other causes. Advances in the prenatal and perinatal care together with technological advent of imaging modalities have enabled timely detection and detailed exploration of symptoms and signs in the neonatal population starting from the fetal life. Although imaging is practically unable to set the diagnosis of viral infection in the fetuses and neonates, moreover to reveal the pathogens, it has, however, the potential to accurately suggest this scenario, map the extent of involvement and direct the investigation and the consultation accordingly. Additionally, it may reveal complications from viral infections that may cause confusion and usually require special treatment (81).

Some imaging findings are highly suggestive of CNS viral infections in fetuses and neonates (82). Familiarity with the clinical course, the route of transmission and the imaging appearances usually proves helpful in reaching the correct diagnosis and in prompting timely treatment. In general, sequelae of an intrauterine infection reflect a combination of the pathogens and the stage of fetal development at which the exposure occurred (83). Congenital infections, occurring during the second and third trimester, may persist in the neonate affecting its general and neurologic status (83). However, as a rule of thumb, the later the diagnosis of congenital infections is made, the more difficult it is to identify the agent. Additionally, the imaging findings may become non-specific and less conspicuous as incomplete white matter myelination may interfere (83).

If maternal viral infection is suspected, combining prenatal ultrasound and fetal magnetic resonance imaging (MRI) may document the extent of tissue damage and therefore contribute to treatment and counselling (84). Neonatal head ultrasound, sometimes computed tomography (CT), but mainly MRI (Figs. 1 and 2) may reveal sequelae from congenital viral infections (i.e., microcephaly, dystrophic periventricular calcifications, brain atrophy), which may even suggest the causative virus, such as cytomegalovirus (CMV) (85). In previously healthy neonates with viral infection, the imaging investigation of CNS begins with head ultrasound and if further imaging investigation is required, MRI is the modality of choice, even in an emergency setting (86). Non-complicated meningitis is easier to be recognised clinically; however, since complications of meningitis, such as abscesses, infarcts, venous thrombosis, or extra-axial empyemas are difficult to diagnose clinically, imaging plays a crucial role (87).

Viral infections of CNS and paediatric intensive care. Viral infections can invade the CNS of children, spreading into the peripheral nervous system (PNS) and more rarely into the CNS (88). The CNS is protected by effective immune responses and multi-layer barriers; however, some viruses enter the CNS with efficiency via the bloodstream or by directly infecting nerves that innervate peripheral tissues, resulting in immune-mediated pathology (89). Viral infections of the CNS more often cause meningitis, characterised by a high fever, headaches, vomiting, photophobia and neck stiffness and encephalitis, which appear with clinical evidence of neurological dysfunction, such as altered mental status, seizures, behavioral changes and focal neurologic signs (90). Other clinical manifestations are myelitis, characterised by weakness, bladder dysfunction, flaccid paralysis and reduced or absent reflexes, radiculitis, which is characterised by weakness, shooting pain, dysesthesia and diminished reflexes and complex syndromes, such as meningoencephalitis and encephalomyelitis. 

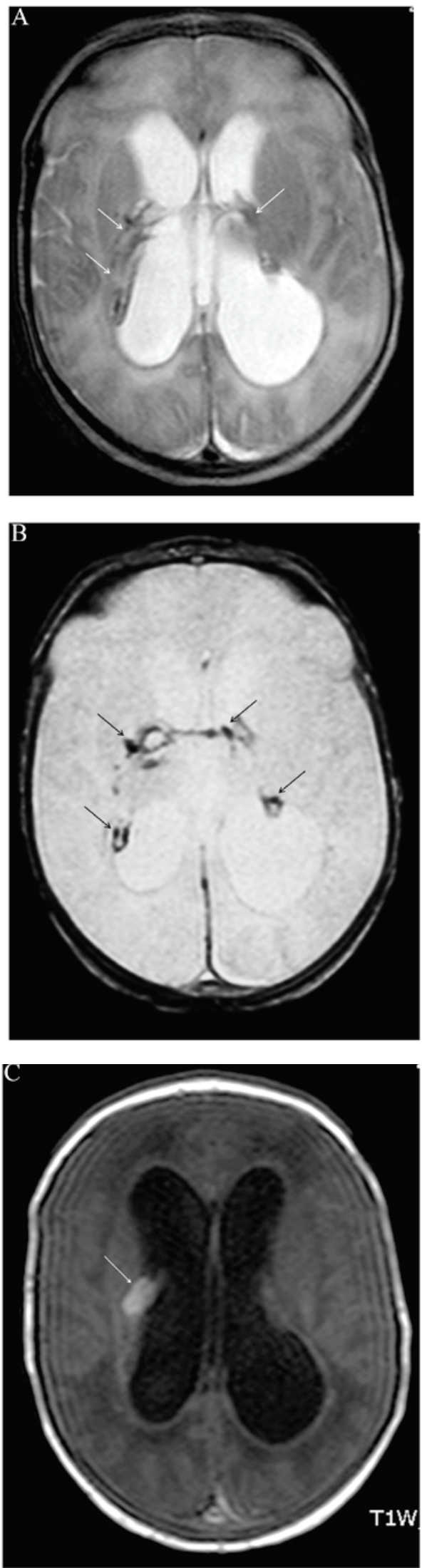

Figure 1. Brain magnetic resonance imaging (MRI) in a term neonate with post-natal enterovirus infection. (A) axial T2-Weighted image through the basal ganglia - white arrows indicate the presence of residual bilateral thalamocaudate groove hemorrhages. (B) Foci of hemosiderin deposits are more conspicuous on axial $\mathrm{T} 2 *$ image, obvious not only in the thalamocaudate grooves, but also along the choroid plexuses (black arrows). (C) This abnorma area (white arrow) is also evident with increased signal intensity on axial T1-Weighted image through the same level.
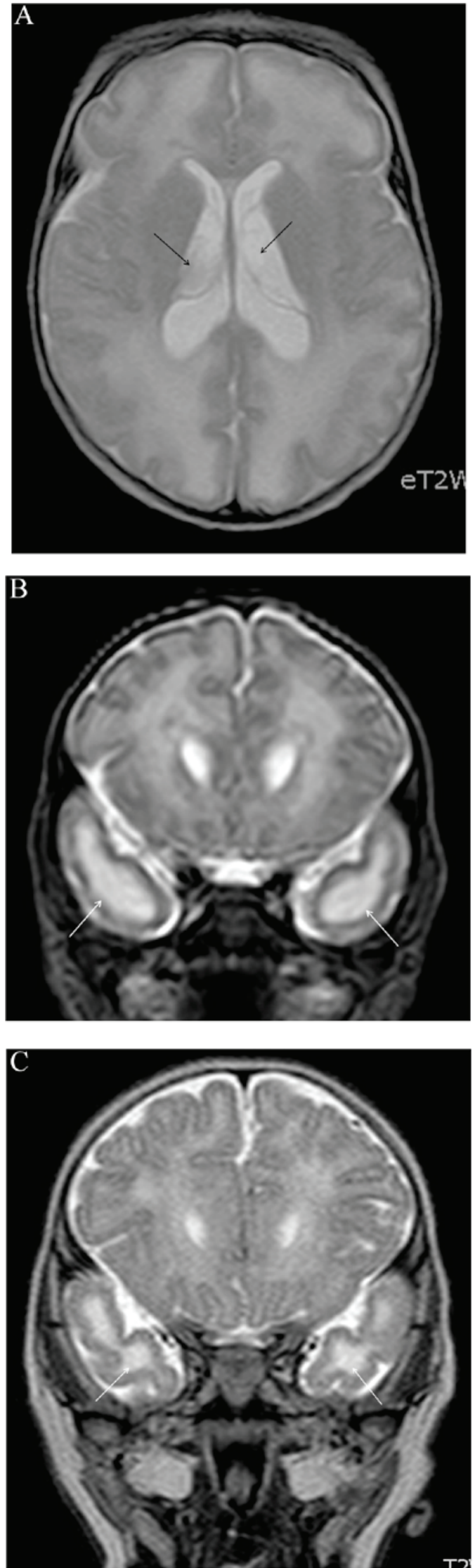

Figure 2. Brain magnetic resonance imaging (MRI) in a neonate with history of third trimester cytomegalovirus (CMV) infection. (A) axial T2-Weighted image through the lateral ventricles - black arrows indicate the presence of intraventricular cysts. (B) Coronal T2-Weighted image reveals signal abnormality in the temporal lobes bilaterally (white arrows). (C) On the 3-month follow-up, same to section b demonstrates persistent signal abnormality in the temporal lobes and additional white matter volume loss (white arrows). 
Table III. Viral causes of central nervous system (CNS) infections in neonates and children.

\begin{tabular}{ll}
\hline Worldwide distribution & $\begin{array}{l}\text { Limited to certain } \\
\text { geographical areas }\end{array}$ \\
\hline Herpes viruses & WNV \\
HSV-1,-2 & Japanese encephalitis virus \\
VZV & St. Louis encephalitis virus \\
EBV & Tick-borne encephalitis virus \\
CMV & Western equine encephalitis virus \\
HHV-6,-7 & Eastern equine encephalitis virus
\end{tabular}

Non-polio enteroviruses

$\mathrm{MuV}$

Measles virus

JC polyomaviruses

BK virus

HSV, herpes simplex virus; VZV, varicella-zoster virus; EBV, EpsteinBarr virus; CMV, cytomegalovirus; HHV, human herpes virus; $\mathrm{MuV}$, mumps virus; WNV, West Nile virus.

Viruses affect different sites of the CNS; enteroviruses, herpes simplex virus 2 (HSV-2) and mumps virus (MuV) are responsible for $>90 \%$ of cases of aseptic meningitis, whereas herpes simplex virus 1 (HSV-1) is the most common cause of encephalitis in developed countries. Other types of herpes viruses, such as Epstein-Barr virus (EBV), CMV, varicellazoster virus (VZV) and human herpes viruses 6 and 7 (HHV-6 and -7) can invade the brain and influence the neurological status of children. Additionally, there are viruses (Table III), such as West Nile virus (WNV), Japanese encephalitis virus, Tick-borne encephalitis virus and Western and Eastern equine encephalitis virus, with certain geographic distribution and their differential diagnosis should be taken into account in cases of children, who have travelled in susceptible areas $(91,92)$. According to the recent data from the Paediatric Intensive Care Unit (PICU) of the 'Aglaia Kyriakou' Children's Hospital (88) in Athens, Greece, among 29 children with CNS infection admitted to the PICU during the past 5 years, 17 patients (59\%) had a viral infection; however, a certain aetiological factor was detected in only 6 of these patients ( 4 cases with influenza, 1 case with enterovirus and 1 case with HHV-7), whereas 2 patients suffered from autoimmune encephalitis.

All patients with suspected CNS infection should undergo lumbar puncture (LP) unless this is contraindicated due to raised intracranial pressure. Investigations of cerebrospinal fluid (CSF) include the total and differential white cell count, red cell count, microscopy, culture, protein, glucose, lactate and a polymerase chain reaction (PCR) test for HSV-1 and HSV-2, VZV, enteroviruses and other possible pathogens depending on the clinical features $(92,93)$. Neuroimaging, a CT scan or preferably MRI, should be performed as soon as possible. An MRI performed within $48 \mathrm{~h}$ of admission is abnormal in approximately $90 \%$ of patients, with some lesions being specific of certain aetiological factors (93). An electroencephalogram (EEG) is considered if seizures are suspected.
All patients with suspected viral encephalitis start treatment with acyclovir and if the PCR test is positive for HSVs or VZV, should continue treatment for at least 14-21 days (93). Corticosteroids can also be used, although their role remains controversial as they have strong immunomodulatory effects, which may facilitate viral replication. Enterovirus infection requires only supportive care and in more severe cases intravenous immunoglobulin (IVIG) alone or in combination with high doses of corticosteroids (90). Other drugs, such as oseltamivir or ganciclovir, are administered according to the underlying viral cause. Viral CNS infections are a life-threatening emergency. Supportive care is crucial and includes airway management, cardiorespiratory support, the maintenance of fluids and electrolyte balance and the management of seizures, according to specific guidelines (94). Approximately $30 \%$ of patients require PICU admission. The overall mortality rates range from 0 to $7 \%$, depending on the pathogen, age and clinical and laboratory findings at the time of presentation. Approximately 35\% of survivors will suffer from some form of permanent disability (seizures, learning problems, motor deficits, developmental delay) with much a higher incidence, two thirds of patients, in HSV encephalitis cases.

$R S V$ and $R V$ infection and their role in asthma. Asthma has been considered for $>30$ years as the most common chronic disease in childhood $(95,96)$; the role of allergy in its development is indeed very significant (97). Other risk factors that have also been associated with the pathogenesis of asthma include prematurity, parental history of asthma, reduced lung size and function, chronic lung disease, neuromuscular or cardiovascular disease, the male sex, low socioeconomic status, Down syndrome, intrauterine tobacco smoke exposure and passive smoking, daycare attendance, early exposure to pets, as well as viral respiratory tract infections in infancy $(96,98-100)$. Among these factors, infections, such as acute viral bronchiolitis, caused by RSV and RV in particular, have been recognised as one of the most significant predictive markers for the development of asthma in later childhood to young adulthood (99-102).

RSV is a common cause of wheezing that seems to dominate in the first year of an infant's life, during the winter period, causing mainly acute bronchiolitis, while RV is being detected as a causative agent for acute bronchiolitis and lower tract viral infections in older infants and children (103). It remains to be clarified though, whether it is the specific viral respiratory infection that plays the causative role in asthmatogenesis or whether viral-induced wheezing is just a marker of predisposed individuals for the subsequent development of asthma (104). It has been well demonstrated that there is an interaction of host factors with viral respiratory infections that promote recurrent virus-induced wheezing and the subsequent development of asthma (101). The synergistic interaction between allergies and viruses can be explained via various mechanisms, such as interferon deficiency, Th2-biased immunity, defective anti-inflammatory response, airway hyper responsiveness and reduced barrier function $(97,103)$. In a recent randomised trial of 429 high-risk infants, treatment with palivizumab of otherwise healthy preterm infants in order to avoid a serious RSV infection was associated with decreased recurrent wheezing rate when compared with the placebo group (105). RSV causes cyto- 
pathic damage to the airway epithelium and by that can affect the function of the epithelium and airway smooth muscle (100).

To date, there is increasing evidence to indicate that RV, the most frequent cause of the common cold in children, can replicate in the lower respiratory tract and can cause exacerbations of asthma $(97,103)$. Certain features of infection with RV, including the stimulation of interleukin (IL)-4,IL-13 and eotaxin production; the immigration of inflammatory cells (eosinophils, macrophages and neutrophils); and subsequent increases in factors considered important for airway remodeling (such as NO and vascular endothelial growth factor), point to the likelihood that RV infection is asthmatogenic (106). Given the burden of asthma, it is of utmost importance that future scientific attempts reveal in detail the causality between viral infections and asthmatogenesis. Thus, better asthma-predictive indices can be developed and more effective strategies for asthma prevention can be scheduled, including research for effective vaccines.

Neonatal mortality and viral infections in ancient Greece. During the 1937 and 1938 American excavations of the Agora, in Athens, a well was excavated that was found to contain a minimum of 459 infant and fetal skeletons (107-109). Although excavated 70 years ago, the details of its contents were never published. As estimated from long bone lengths, the age of the infants ranged from 26 weeks in utero to 6 months post-term, with a peak at 38-40 weeks (110). The cause of death for the infants in the Agora's well has been the topic of much speculation over the past 70 years. Suggestions have included war-related famine or epidemic disease, human sacrifice and large-scale infanticide. One of the goals of this project was to evaluate the evidence for pathologies in the infants in order to evaluate the causes of death. Infant death rates from natural causes in the ancient world were very high, and up to $50 \%$ of neonates may have died early in the postnatal period (111). In addition, approximately $15 \%$ of these skeletons are from infants born pre-term, as young as 26 weeks in utero. Many of these were probably either stillborn or died from complications associated with prematurity, including respiratory distress and problems with thermoregulation.

The cranial bones provide evidence for pathologies and possible infectious causes of death. Most of the lesions are diffuse areas of new bone formed on the endocranial surface. The cruciate eminence of the occipital bone was the most common location for endocranial reactive bone in the infants, and this corresponds to the findings in other ancient and modern skeletal collections. Lesions have also been identified on the parietal and frontal bones, often in areas of venous drainage. The greater wing and body of the sphenoid bone also exhibited endocranial proliferative bone lesions. It has been found that that lesions extending beyond the cruciate eminence of the occipital, and hair-on-end lesions are more likely to be pathological, rather than indicative of than normal bone growth (112). More than $30 \%$ of the occipital squamae in this collection exhibited clear pathological bone deposits.

Infections and birth-related trauma are thought to have caused most of these lesions. Infections of the meninges are thought to activate the periosteal membrane, resulting in new bone deposition, but the exact mechanism is not clear (112). Infectious pathogens were commonly introduced through cutting the umbilical cord, and through cultural and dietary practices. It is likely that infants in ancient Athens suffered from the same array of viral infections to which modern infants are prone, including HSV, influenza virus, corona virus, enterovirus, EBV and arbovirus (113). The perinatal period in ancient Athens was perilous, with considerable risk from viral and bacterial infections. The skeletons from this well provide a brief glimpse into the short lives and early deaths of the youngest Athenians.

Continuing medical education in Paediatric Virology. To provide the optimal care to paediatric patients, a paediatrician should commit to lifelong learning (114), following the quote by the Athenian Solon (640-558 BC), one of the Seven Wise Men of Ancient Greece, 'I grow old learning something new every

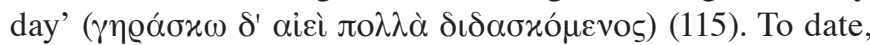
the importance of continuing medical education (CME), also known as continuing medical development (CMD), has been recognised as a method of improving the quality of paediatric care by several paediatric organisations and institutions, such as the European Academy of Paediatrics (116) and the $\mathrm{RCPCH}$ (117). It is a professional responsibility for all practicing paediatricians to maintain, develop and increase their knowledge, clinical skills and professional performance with an aim to enhance their clinical effectiveness and competence (118-122). Paediatric Virology is indeed a new educational challenge with rapidly increasing and changing educational needs and preferences (123). This is fostered by several developments in the fields of Clinical Virology and Molecular Medicine, emerging viral diseases as well as technical innovations, which have expanded our diagnostic and therapeutic approaches towards neonatal and paediatric viral infections.

The feedback received from the participants of the 1st and the 2nd Workshop on Paediatric Virology held in 2015 and 2016, respectively, in Athens, highlighted the need for CME (114). CME in Paediatric Virology must not only emphasise the acquisition of knowledge, but also instruct paediatricians in the process of decision making. Self-directed learning activity should be encouraged; however, CME in Paediatric Virology should also instill collegiality, interaction and collaboration between disciplines. Without a doubt, Paediatric Virologists should have a leading role in CME in Paediatric Virology focusing on academic excellence and state-of-the-art medical education of practicing paediatricians. Further discussion is required on how different educational activities, such as on-line learning, interactive case-based workshops and creation of educational e-platforms, can increase their potential worth for the promotion of Peadiatrics and Public Health.

\section{Acknowledgements}

The authors would like to thank the plenary lecturers, the chair persons and the speakers of the '3rd Workshop on Paediatric Virology' for their significant contribution in providing the most up-to-date information. The authors would also like to thank all the participants, who attended the workshop and provided feedback so that further research on improving the programme can be achieved for the future. We would like to thank Nobelist laureate Professor Harald zur Hausen, Emeritus Professor of Virology at the University of Freiburg, for his detailed corrections and comments on our manuscript. We would also like to thank Dr Neda Voutsa-Perdiki, former Director of Exfoliative 
Cytology at the University of Florida, USA and academic student of Dr George N. Papanicolaou, for her touching presence in our workshop. Last but not least, this workshop would not have been possible without the dedicated hard work and strong commitment from the Congress Secretariat, the members of the PVSG and the whole organising team of the '22nd World Congress on Advances in Oncology' and the '20th International Symposium on Molecular Medicine' for developing the scientific programme, coordinating and guaranteeing the success of this scientific event.

\section{Competing interests}

Demetrios Spandidos is the Editor-in-Chief for the journal, but had no personal involvement in the reviewing process, or any influence in terms of adjudicating on the final decision, for this article.

\section{References}

1. Greenough A, Osborne J and Sutherland S (eds): Congenital, Perinatal, and Neonatal Infections. Churchill Livingstone, Edinburgh, 1992.

2. Shulman ST: The history of pediatric infectious diseases. Pediatr Res 55: 163-176, 2004.

3. Starr M: Paediatric infectious diseases: The last 50 years. J Paediatr Child Health 51: 12-15, 2015.

4. Mammas IN, Greenough A, Theodoridou M, Kramvis A, Christaki I, Koutsaftiki C, Koutsaki M, Portaliou DM, Kostagianni G, Panagopoulou P, Sourvinos G and Spandidos DA: Current views and advances on Paediatric Virology: An update for paediatric trainees. Exp Ther Med 11: 6-14, 2016.

5. Mammas IN, Greenough A, Theodoridou M and Spandidos DA: Paediatric Virology: A new paediatric subspecialty? A proposal at the Workshop on Paediatric Virology, Athens, October 10, 2015. Exp Ther Med 11: 3-5, 2016.

6. zur Hausen H: Paediatric Virology and Oncology: Virus persistence and the important first years of life. Int J Mol Med 40 Suppl 41, 2017.

7. zur Hausen $\mathrm{H}$, Bund $\mathrm{T}$ and de Villiers EM: Infectious agents in bovine red meat and milk and their potential role in cancer and other chronic diseases. Curr Top Microbiol Immunol 407: 83-116, 2017.

8. Greenough A, MacBean V, Lunt A, Drysdale SB, Rafferty GF and Peacock JL: The long term impact of viral infections on prematurely born infants. Int J Mol Med 40: Suppl 41, 2017.

9. Broughton S, Bhat R, Roberts A, Zuckerman M, Rafferty G and Greenough A: Diminished lung function, RSV infection, and respiratory morbidity in prematurely born infants. Arch Dis Child 91: 26-30, 2006.

10. Drysdale SB, Wilson T, Alcazar M, Broughton S, Zuckerman M, Smith M, Rafferty GF, Johnston SL and Greenough A: Lung function prior to viral lower respiratory tract infections in prematurely born infants. Thorax 66: 468-473, 2011.

11. Drysdale SB, Prendergast M, Alcazar M, Wilson T, Smith M, Zuckerman M, Broughton S, Rafferty GF, Johnston SL, Hodemaekers HM, et al: Genetic predisposition of RSV infection-related respiratory morbidity in preterm infants. Eur J Pediatr 173: 905-912, 2014.

12. Drysdale SB, Lo J, Prendergast M, Alcazar M, Wilson T, Zuckerman M, Smith M, Broughton S, Rafferty GF, Peacock JL, et al: Lung function of preterm infants before and after viral infections. Eur J Pediatr 173: 1497-1504, 2014.

13. Broughton S, Roberts A, Fox G, Pollina E, Zuckerman M, Chaudhry S and Greenough A: Prospective study of healthcare utilisation and respiratory morbidity due to RSV infection in prematurely born infants. Thorax 60: 1039-1044, 2005.

14. Greenough A, Alexander J, Boit P, Boorman J, Burgess S, Burke A, Chetcuti PA, Cliff I, Lenney W, Lytle T, et al: School age outcome of hospitalisation with respiratory syncytial virus infection of prematurely born infants. Thorax 64: 490-495, 2009.

15. Chidekel AS, Rosen CL and Bazzy AR: Rhinovirus infection associated with serious lower respiratory illness in patients with bronchopulmonary dysplasia. Pediatr Infect Dis J 16: 43-47, 1997.
16. Drysdale SB, Alcazar-Paris M, Wilson T, Smith M,Zuckerman M, Broughton S, Rafferty GF, Peacock JL, Johnston SL and Greenough A: Rhinovirus infection and healthcare utilisation in prematurely born infants. Eur Respir J 42: 1029-1036, 2013.

17. MacBean V, Lunt A, Drysdale S, Rafferty GF and Greenough A: Predicting healthcare outcomes in prematurely born infants using cluster analysis. Arch Dis Child 102: A190-A191, 2017.

18. MacBean V, Yarzi MN, Drysdale S, Rafferty GF and Greenough A: Impact of respiratory viral infections on school age outcomes in prematurely born children. Am J Respir Crit Care Med 195: A2169, 2017.

19. Theodoridou M: Immigration crisis and vaccination policy. Int $\mathbf{J}$ Mol Med 40: S41, 2017.

20. United Nations High Commissioner for Refugees (UNHCR): The sea route to Europe: The Mediterranean passage in the age of refugees, 2015. http://www.unhcr.org/5592bd059.pdf.

21. Medecins Sans Frontieres (MSF): EU Migration Crisis Update - February 2016, 2016. http://www.msf.org/en/article/ eu-migration-crisis-update-february-2016.

22. International Organization for Migration (IOM): IOM: 170.553 migrants/refugees have arrived in Greece in 2016, 2016. https:// greece.iom.int/en/news/iom-170553-migrantsrefugees-have-arrivedgreece-2016.

23. REACH: Situation overview: European migration crisis, Western Balkans, December 2015. www.reachresourcecentre.info/ system/files/resource-documents/reach_eu_situation_overview_ european_migration_trends_december_2015_5.pdf.

24. Mipatrini D, Stefanelli P, Severoni S and Rezza G: Vaccinations in migrants and refugees: A challenge for European health systems. A systematic review of current scientific evidence. Pathog Glob Health 111: 59-68, 2017.

25. World Health Organization (WHO): Refugee and migrant health, 2017. http://www.who.int/migrants/en/.

26. Hellenic Ministry of Health: Report. Vaccination on Points of care of refugees/migrants, February 2017. http://www.moh.gov.gr/articles/ ministry/grafeio-typoy/press-releases/4489-ekthesh-emboliastikhskalypshs-paidiwn-metanastwn-kai-prosfygwn.

27. Giambi C, Del Manso M, Dente MG, Napoli C, Montaño-Remacha C, Riccardo F and Declich S; Network For The Control Of Cross-Border Health Threats In The Mediterranean Basin And Black Sea For The ProVacMed Project: Immunization strategies targeting newly arrived migrants in non-EU countries of the Mediterranean Basin and Black Sea. Int J Environ Res Public Health 14: 14, 2017.

28. World Health Organization (WHO): World Health Organization Global Hepatitis Report 2017, 2017. http://www.who.int/hepatitis/ publications/global-hepatitis-report2017/en/.

29. Kramvis A: Mother to child transmission of hepatitis B and $C$ viruses. Int J Mol Med 40: S39, 2017.

30. Shimakawa Y, Lemoine M, Bottomley C, Njai HF, Ndow G, Jatta A, Tamba S, Bojang L, Taal M, Nyan O, et al: Birth order and risk of hepatocellular carcinoma in chronic carriers of hepatitis B virus: A case-control study in The Gambia. Liver Int 35: 2318-2326, 2015

31. Kramvis A: The clinical implications of hepatitis B virus genotypes and $\mathrm{HBeAg}$ in pediatrics. Rev Med Virol 26: 285-303, 2016.

32. Tovo PA, Calitri C, Scolfaro C, Gabiano C and Garazzino S: Vertically acquired hepatitis $\mathrm{C}$ virus infection: Correlates of transmission and disease progression. World J Gastroenterol 22: 1382-1392, 2016.

33. World Health Organization (WHO): Global Health Sector Strategy on viral hepatitis 2016-2021, 2016. http://www.who.int/ hepatitis/strategy2016-2021/ghss-hep/en/.

34. Schillie S, Walker T, Veselsky S, Crowley S, Dusek C, Lazaroff J, Morris SA, Onye K, Ko S, Fenlon N, et al: Outcomes of infants born to women infected with hepatitis B. Pediatrics 135: e1141-e1147, 2015.

35. Brown RS Jr, McMahon BJ, Lok AS, Wong JB, Ahmed AT, Mouchli MA, Wang Z, Prokop LJ, Murad MH and Mohammed K: Antiviral therapy in chronic hepatitis B viral infection during pregnancy: A systematic review and meta-analysis. Hepatology 63: 319-333, 2016

36. Pan CQ, Zou HB, Chen Y, Zhang X, Zhang H, Li J and Duan Z: Cesarean section reduces perinatal transmission of hepatitis $B$ virus infection from hepatitis B surface antigen-positive women to their infants. Clin Gastroenterol Hepatol 11: 1349-1355, 2013.

37. Chen X, Chen J, Wen J, Xu C, Zhang S, Zhou YH and Hu Y: Breastfeeding is not a risk factor for mother-to-child transmission of hepatitis B virus. PLoS One 8: e55303, 2013.

38. Benova L, Mohamoud YA, Calvert C and Abu-Raddad LJ: Vertical transmission of hepatitis $C$ virus: Systematic review and meta-analysis. Clin Infect Dis 59: 765-773, 2014. 
39. Elrazek A, Amer M, El-Hawary B, Salah A, Bhagavathula AS, Alboraie $M$ and Saab S: Prediction of HCV vertical transmission: What factors should be optimized using data mining computational analysis. Liver Int 37: 529-533, 2017.

40. Rusan M: Human papillomavirus infections in children: Should we be vaccinating earlier? Int J Mol Med 40: S40, 2017.

41. Doorbar J, Quint W, Banks L, Bravo IG, Stoler M, Broker TR and Stanley MA: The biology and life-cycle of human papillomaviruses. Vaccine 30 (Suppl 5): F55-F70, 2012

42. Kajitani N, Satsuka A, Kawate A and Sakai H: Productive lifecycle of human papillomaviruses that depends upon squamous epithelial differentiation. Front Microbiol 3: 152, 2012.

43. Lehoux M, D'Abramo CM and Archambault J: Molecular mechanisms of human papillomavirus-induced carcinogenesis. Public Health Genomics 12: 268-280, 2009.

44. Trottier H and Burchell AN: Epidemiology of mucosal human papillomavirus infection and associated diseases. Public Health Genomics 12: 291-307, 2009

45. Forman D, de Martel C, Lacey CJ, Soerjomataram I, Lortet-Tieulent J, Bruni L, Vignat J, Ferlay J, Bray F, Plummer M, et al: Global burden of human papillomavirus and related diseases. Vaccine 30 (Suppl 5): F12-F23, 2012.

46. Syrjänen S: Current concepts on human papillomavirus infections in children. APMIS 118: 494-509, 2010.

47. Mammas IN, Sourvinos G and Spandidos DA: Human papilloma virus (HPV) infection in children and adolescents. Eur J Pediatr 168: 267-273, 2009

48. Tiggelaar SM, Lin MJ, Viscidi RP, Ji J and Smith JS Age-specific human papillomavirus antibody and deoxyribonucleic acid prevalence: A global review. J Adolesc Health 50: 110-131, 2012.

49. Silverberg MJ, Thorsen P, Lindeberg H, Grant LA and Shah KV: Condyloma in pregnancy is strongly predictive of juvenile-onset recurrent respiratory papillomatosis. Obstet Gynecol 101: 645-652, 2003

50. Michels KB and zur Hausen H: HPV vaccine for all. Lancet 374: 268-270, 2009

51. Ontario. Getting the HPV vaccine. Government of Ontario, 2017. http://www.health.gov.on.ca/en/ms/hpv/.

52. Centers for Disease Control and Prevention (CDC): HPV Vaccines: Vaccinating Your Preteen or Teen, 2016. https://www. cdc.gov/hpv/parents/vaccine.html.

53. Paul KT: 'Saving lives': Adapting and adopting Human Papilloma Virus (HPV) vaccination in Austria. Soc Sci Med 153: 193-200, 2016.

54. World Health Organization (WHO): Human papillomavirus vaccines: WHO position paper, May 2017-Recommendations. Vaccine, 2017 (In press).

55. Palefsky JM, Giuliano AR, Goldstone S, Moreira ED Jr, Aranda C, Jessen H, Hillman R, Ferris D, Coutlee F, Stoler MH, et al: HPV vaccine against anal HPV infection and anal intraepithelial neoplasia. N Engl J Med 365: 1576-1585, 2011.

56. Anic GM and Giuliano AR: Genital HPV infection and related lesions in men. Prev Med 53 (Suppl 1): S36-S41, 2011.

57. Herrero R, Quint W, Hildesheim A, Gonzalez P, Struijk L, Katki HA, Porras C, Schiffman M, Rodriguez AC, Solomon D, et al; CVT Vaccine Group: Reduced prevalence of oral human papillomavirus (HPV) 4 years after bivalent HPV vaccination in a randomized clinical trial in Costa Rica. PLoS One 8: e68329, 2013.

58. Drolet M, Bénard É, Boily MC, Ali H, Baandrup L, Bauer H, Beddows S, Brisson J, Brotherton JM, Cummings T, et al: Population-level impact and herd effects following human papillomavirus vaccination programmes: A systematic review and meta-analysis. Lancet Infect Dis 15: 565-580, 2015.

59. Vichnin M, Bonanni P, Klein NP, Garland SM, Block SL, Kjaer SK, Sings HL, Perez G, Haupt RM, Saah AJ, et al: An overview of quadrivalent human papillomavirus vaccine safety: 2006 to 2015. Pediatr Infect Dis J 34: 983-991, 2015.

60. Melidou A: Intranasal live-attenuated influenza vaccination in children: Evidence, limitations and proposals. Int J Mol Med 40: S39, 2017

61. Rodgers L, Pabst LJ and Chaves SS: Increasing uptake of live attenuated influenza vaccine among children in the United States, 2008-2014. Vaccine 33: 22-24, 2015.

62. Centers for Disease Prevention and Control (CDC): Seasonal Influenza: Flu Basics, 2016. https://www.cdc.gov/flu/about/ season/flu-season-2016-2017.htm.
63. Pebody R, Warburton F, Ellis J, Andrews N, Potts A, Cottrell S, Johnston J, Reynolds A, Gunson R, Thompson C, et al: Effectiveness of seasonal influenza vaccine for adults and children in preventing laboratory-confirmed influenza in primary care in the United Kingdom: 2015/16 end-of-season results. Euro Surveill 21: 21, 2016.

64. Nohynek H, Baum U, Syrjänen R, Ikonen N, Sundman J and Jokinen J: Effectiveness of the live attenuated and the inactivated influenza vaccine in two-year-olds - a nationwide cohort study Finland, influenza season 2015/16. Euro Surveill 21: 21, 2016.

65. Kwong JC, Pereira JA, Quach S, Pellizzari R, Dusome E, Russell ML, Hamid JS, Feinberg Y, Winter AL, Gubbay JB, et al; Public Health Agency of Canada/Canadian Institutes of Health Research Influenza Research Network (PCIRN) Program Delivery and Evaluation Group: Randomized evaluation of live attenuated vs. inactivated influenza vaccines in schools (RELATIVES) cluster randomized trial: Pilot results from a household surveillance study to assess direct and indirect protection from influenza vaccination. Vaccine 33: 4910-4915, 2015.

66. Caspard H, Coelingh KL, Mallory RM and Ambrose CS: Association of vaccine handling conditions with effectiveness of live attenuated influenza vaccine against $\mathrm{H} 1 \mathrm{~N} 1 \mathrm{pdm} 09$ viruses in the United States. Vaccine 34: 5066-5072, 2016.

67. Caspard H,Heikkinen T, Belshe RB and Ambrose CS: A systematic review of the efficacy of live attenuated influenza vaccine upon revaccination of children. Hum Vaccin Immunother 12: 1721-1727, 2016.

68. Leung VKY, Carolan LA, Worth LJ, Harper SA, Peck H, Tilmanis D, Laurie KL, Slavin MA and Sullivan SG: Influenza vaccination responses: Evaluating impact of repeat vaccination among health care workers. Vaccine 35: 2558-2568, 2017.

69. Simpson CR, Lone NI, Kavanagh K, Robertson C, McMenamin J, von Wissmann B, et al: Evaluating the effectiveness, impact and safety of live attenuated and seasonal inactivated influenza vaccination: protocol for the Seasonal Influenza Vaccination Effectiveness II (SIVE II) study. BMJ Open 7: e014200, 2017. 70.

70. Korovessi P: Probiotics and viral infections in childhood. Int $\mathbf{J}$ Mol Med 40: S39, 2017.

71. Food and Agriculture Organization of the United Nations, World Health Organization: Guidelines for the Evaluation of Probiotics in Food. Report of a Joint FAO/WHO Working Group on Drafting Guidelines for the Evaluation of Probiotics in Food. London, Ontario, Canada, April 30 and May 1, 2002.

72. Ahrne S and Hagslatt ML: Effect of lactobacilli on paracellular permeability in the gut. Nutrients 3: 104-117, 2011.

73. Morais MB and Jacob CM: The role of probiotics and prebiotics in pediatric practice. J Pediatr (Rio J) 82 (Suppl 5): S189-S197, 2006.

74. Guarino A, Lo Vecchio A and Canani RB: Probiotics as prevention and treatment for diarrhea. Curr Opin Gastroenterol 25: 18-23, 2009.

75. Szajewska H, Guarino A, Hojsak I, Indrio F, Kolacek S, Shamir R, Vandenplas Y and Weizman Z; European Society for Pediatric Gastroenterology, Hepatology and Nutrition: Use of probiotics for management of acute gastroenteritis: A position paper by the ESPGHAN Working Group for Probiotics and Prebiotics. J Pediatr Gastroenterol Nutr 58: 531-539, 2014.

76. Guarino A, Ashkenazi S, Gendrel D, Lo Vecchio A, Shamir R and Szajewska H; European Society for Pediatric Gastroenterology, Hepatology, and Nutrition; European Society for Pediatric Infectious Diseases: European Society for Pediatric Gastroenterology, Hepatology, and Nutrition/European Society for Pediatric Infectious Diseases evidence-based guidelines for the management of acute gastroenteritis in children in Europe; Update 2014. J Pediatr Gastroenterol Nutr 59: 132-152, 2014

77. Hao Q, Lu Z, Dong BR, Huang CQ and Wu T: Probiotics for preventing acute upper respiratory tract infections. Cohrane Database Syst Rev 9: CD006895, 2015. doi: 10.1002/14651858. CD006895.pub2.

78. Esposito S, Rigante D and Principi N: Do children's upper respiratory tract infections benefit from probiotics? BMC Infect Dis 14: 194, 2014.

79. Allan GM and Arroll B: Prevention and treatment of the common cold: Making sense of the evidence. CMAJ 186: 190-199, 2014.

80. Amaral MA, Guedes GHBF, Epifanio M, Wagner MB, Jones MH and Mattiello R: Network meta-analysis of probiotics to prevent respiratory infections in children and adolescents. Pediatr Pulmonol 52: 833-843, 2017.

81. Papaioannou G: Foetal and neonatal brain imaging in viral infections. Int J Mol Med 40: S39, 2017.

82. Lo CP and Chen CY: Neuroimaging of viral infections in infants and young children. Neuroimaging Clin N Am 18: 119-132, 2008. 
83. Shaw DWW and Cohen WA: Viral infections of the CNS in children: Imaging features. AJR Am J Roentgenol 160: 125-133, 1993.

84. Verstraelen H, Vanzieleghem B, Defoort P, Vanhaesebrouck P and Temmerman M: Prenatal ultrasound and magnetic resonance imaging in fetal varicella syndrome: Correlation with pathology findings. Prenat Diagn 23: 705-709, 2003.

85. Sanchez TR, Datlow MD and Nidecker AE: Diffuse periventricular calcification and brain atrophy: A case of neonatal central nervous system cytomegalovirus infection. Neuroradiol J 29: 314-316, 2016

86. Gupta K, Banerjee A, Saggar K, Ahluwalia A and Saggar K: A prospective study of magnetic resonance imaging patterns of central nervous system infections in pediatric age group and young adults and their clinico-biochemical correlation. J Pediatr Neurosci 11: 46-51, 2016.

87. Acosta JH, Rantes CI, Arbelaez A, Restrepo F and Castillo M: Noncongenital central nervous system infections in children: Radiology review. Top Magn Reson Imaging 23: 153-164, 2014.

88. Papatheodoropoulou AE: Viral infections of central nervous system in children. Int J Mol Med 40: S40, 2017.

89. Koyuncu OO, Hogue IB and Enquist LW: Virus infections in the nervous system. Cell Host Microbe 13: 379-393, 2013.

90. Teoh HL, Mohammad SS, Britton PN, Kandula T, Lorentzos MS, Booy R, Jones CA, Rawlinson W, Ramachandran V Rodriguez ML, et al: Clinical characteristics and functional motor outcomes of Enterovirus 71 neurological disease in children. JAMA Neurol 73: 300-307, 2016.

91.Erasmus M: Viral infections of Central Nervous System. CME 29: 190-193, 2011.

92. Venkatesan A, Tunkel AR, Bloch KC, Lauring AS, Sejvar J, Bitnun A, Stahl JP, Mailles A, Drebot M, Rupprecht CE, et al International Encephalitis Consortium: Case definitions, diagnostic algorithms, and priorities in encephalitis: Consensus statement of the international encephalitis consortium. Clin Infect Dis 57: 1114-1128, 2013.

93. Kneen R, Michael BD, Menson E, Mehta B, Easton A, Hemingway C, Klapper PE, Vincent A, Lim M, Carrol E, et al; National Encephalitis Guidelines Development and Stakeholder Groups: Management of suspected viral encephalitis in children - Association of British Neurologists and British Paediatric Allergy, Immunology and Infection Group national guidelines. J Infect 64: 449-477, 2012.

94. Pillai SC, Hacohen Y, Tantsis E, Prelog K, Merheb V, Kesson A, Barnes E, Gill D, Webster R, Menezes M, et al: Infectious and autoantibody-associated encephalitis: Clinical features and long-term outcome. Pediatrics 135: e974-e984, 2015.

95. Koutsaftiki C: RSV and rhinovirus infection in early childhood and their role in asthma. Int J Mol Med 40: S40, 2017.

96. Gidaris D, Urquhart D and Anthracopoulos MB: 'They said it was bronchiolitis; is it going to turn into asthma doctor?'. Respirology 19: 1158-1164, 2014.

97. Kloepfer KM and Gern JE: Virus/allergen interactions and exacerbations of asthma. Immunol Allergy Clin North Am 30: 553-563, vii, 2010.

98. Chong Neto HJ, Rosario N, Solé D and Mallol J: Associated factors for recurrent wheezing in infancy. Allergy 65: 406-407, 2010.

99. Jackson DJ, Gangnon RE, Evans MD, Roberg KA, Anderson EL, Pappas TE, Printz MC, Lee WM, Shult PA, Reisdorf E, et al: Wheezing rhinovirus illnesses in early life predict asthma development in high-risk children. Am J Respir Crit Care Med 178: 667-672, 2008.

100. Kakumanu S: Virus-induced wheezing and asthma: An overview. UpToDate, 2017. https://www.uptodate.com/contents/ virus-induced-wheezing-and-asthma-an-overview.

101. Gern JE: Viral respiratory infection and the link to asthma Pediatr Infect Dis J 27 (10 Suppl): S97-S103, 2008.

102. Rantala AK, Jaakkola MS, Mäkikyrö EM, Hugg TT and Jaakkola JJ: Early respiratory infections and the development of asthma in the first 27 years of life. Am J Epidemiol 182: 615-623, 2015.

103. Gern JE: The ABCs of rhinoviruses, wheezing, and asthma. J Virol 84: 7418-7426, 2010
104. Bartlett NW, McLean GR, Chang YS and Johnston SL: Genetics and epidemiology: Asthma and infection. Curr Opin Allergy Clin Immunol 9: 395-400, 2009.

105. Blanken MO, Rovers MM, Molenaar JM, Winkler-Seinstra PL, Meijer A, Kimpen JL and Bont L; Dutch RSV Neonatal Network: Respiratory syncytial virus and recurrent wheeze in healthy preterm infants. N Engl J Med 368: 1791-1799, 2013.

106. Stone CA Jr and Miller EK: Understanding the association of human rhinovirus with asthma. Clin Vaccine Immunol 23: 6-10, 2015.

107.Liston MA: The causes and contexts of perinatal mortality in ancient Greece: A case study from the 'bone well' of the Athenian Agora. Int J Mol Med 40: S40, 2017.

108.Liston MA, Rotroff SI and Snyder LM: The Agora bone well. Hesperia Supplements. Am Sch Class Stud Athens (In press).

109. Liston MA and Rotroff SI: Babies in the well: Archaeological evidence for newborn disposal in Hellenistic Greece. In The Oxford Handbook of Childhood and Education in the Classical World. Parkin T and Evans-Grubbs J (eds). Oxford University Press, Oxford, 2013. https://doi.org/10.1093/ oxfordhb/9780199781546.013.003.

110. Scheuer L and Black S: Developmental Juvenile Osteology. Elsevier Academic Press, London, 2000.

111. Becker MJ: Etruscan infants: children's cemeteries at Tarquinia, Italy, as indicators of an age of transition. In: (Re)thinking the Little Ancestor: New Perspectives on the Archaeology of Infancy and Childhood. Lally M and Moore A (eds). Archaeopress, Oxford, 2011.

112.Lewis ME: Endocranial lesions in non-adult skeletons: Understanding their aetiology. Int J Osteoarchaeol 14: 82-97, 2004.

113. Santos RP and Tristram D: A practical guide to the diagnosis, treatment, and prevention of neonatal infections. Pediatr Clin North Am 62: 491-508, 2015.

114. Mammas IN and Spandidos DA: Paediatric Virology: Focusing on medical education and training research. Int J Mol Med 40: S25, 2017.

115.Plutarch: Vioi Paralliloi; Solon - Poplikolas. Vol. 1. Kaktos Editions, 1992. (In Greek)

116. European Academy of Paediatrics: Continuous Medical Education (CME), 2017. http://eapaediatrics.eu/working-group/ continuous-medical-education-cme/

117. Royal College of Paediatrics and Child Health: Continuing Professional Development (CPD), 2017. https://www.rcpch.ac. uk/training-examinations-professional-development/continuingprofessional-development-cpd/continuing-pr.

118. D'Apuzzo V, Helwig H and Siimes M; Confederation of European Specialists in Paediatrics Working Group on Continuing Medical Education: Charter on continuing medical education in paediatrics in the European Union. Eur J Pediatr 157: 192-193, 1998.

119. Djuricich AM, Turco MG and Sachdeva AK: Changing continuing medical education. JAMA 314: 1072-1073, 2015.

120.Holl RA and Alden ER: Continuing medical education in Europe. Pediatr Rev 23: 335-336, 2002.

121. Costa A, Van Hemelryck F, Aparicio A, Gatzemeier W, Leer JW, Maillet B and Hossfeld DK: Continuing medical education in Europe: Towards a harmonised system. Eur J Cancer 46: 2340-2343, 2010 .

122. James E: Clinical education in paediatrics. J Child Health Care 2: 178-181, 1998.

123. Mammas IN, Theodoridou M, Kramvis A, Thiagarajan $\mathrm{P}$, Gardner S, Papaioannou G, Melidou A, Koutsaki M,KostagianniG, Achtsidis V, et al: Paediatric Virology: A rapidly increasing educational challenge. Exp Ther Med 13: 364-377, 2017.

This work is licensed under a Creative Commons Attribution-NonCommercial-NoDerivatives 4.0 International (CC BY-NC-ND 4.0) License. 